\title{
Multicomposite Nanostructured Hematite-Titania Photoanodes with Improved Oxygen Evolution: The Role of the Oxygen Evolution Catalyst
}

\author{
Mario Bärtsch, ${ }^{\dagger}$ Marta Sarnowska, ${ }^{\ddagger}$ Olga Krysiak, ${ }^{\ddagger}$ Christoph Willa, $^{\dagger}$ Christian Huber, $^{\dagger}$ Lex Pillatsch, $^{\S}$ \\ Sandra Reinhard, ${ }^{\dagger}$ and Markus Niederberger* ${ }^{* \dagger}$ \\ ${ }^{\dagger}$ Laboratory for Multifunctional Materials, Department of Materials, ETH Zurich, Vladimir-Prelog-Weg 5, 8093 Zurich, Switzerland \\ ${ }^{\ddagger}$ Centre of New Technologies (CeNT), University of Warsaw, Żwirki i Wigury 93, 02-089 Warsaw, Poland \\ ${ }^{\S}$ Laboratory for Mechanics of Materials and Nanostructures, Swiss Federal Laboratories for Materials Science and Technology \\ (EMPA), Feuerwerkerstrasse 39, 3602 Thun, Switzerland
}

Supporting Information

ABSTRACT: We present a sol-gel processed hematitetitania-based photoanode, which exhibits a photocurrent of up to $2.5 \mathrm{~mA} / \mathrm{cm}^{2}$ at $1.23 \mathrm{~V}_{\mathrm{RHE}}$ under simulated $\mathrm{AM} 1.5 \mathrm{G}$ illumination $\left(100 \mathrm{~mW} / \mathrm{cm}^{2}\right)$ thanks to the addition of an amorphous cocatalyst with the nominal composition $\mathrm{Fe}_{20} \mathrm{Cr}_{40} \mathrm{Ni}_{40} \mathrm{O}_{x}$. To unveil the role of the cocatalyst interconnected to the photoanode, we performed impedance measurements. According to the one order of magnitude
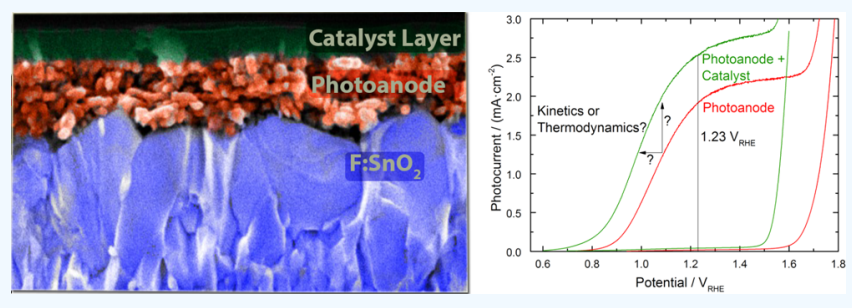
higher value for the capacitance associated with surface states $\left(C_{S S}\right)$ compared to the bare photoanode, the function of the catalyst-photoanode interface resembles that of a $p-n$-like junction. In addition, the charge transfer resistance associated with charge transfer processes from surface states $\left(R_{\mathrm{ct}, \mathrm{ss}}\right)$ was unchanged at potentials between 0.8 and $1.1 \mathrm{~V}_{\mathrm{RHE}}$ after adding the cocatalyst, indicating that the catalyst has a negligible effect on the hole transport to the electrolyte. The understanding of the role of oxygen evolution catalysts (OECs) in conjunction with the photoanodes is particularly important for water splitting because most OECs are studied separately at considerably higher potentials compared to the potentials at which photoanode materials are operated.

\section{INTRODUCTION}

The urge to replace fossil fuels by a renewable energy source will be predominant in this century to limit global warming. Although solar cells exhibit excellent quantum efficiencies, losses occur when electric power is stored in batteries to bypass peaks with high power generation. With direct photoelectrochemical water splitting, one has the clear advantage to transform sunlight directly into hydrogen, which has a high energy density per unit weight. ${ }^{1}$ Compared to those of $\mathrm{TiO}_{2}$ and $\mathrm{WO}_{3}$, hematite photoanodes exhibit a high theoretically achievable solar-to-hydrogen efficiency (15.5\%) coinciding with its narrow band gap of ca. $2.1 \mathrm{eV}^{2,3}$ However, inherent drawbacks such as poor $\mathrm{e}^{-}$and $\mathrm{h}^{+}$conductivity, low charge carrier mobility and lifetime, large visible light absorption depth, and slow water oxidation kinetics limit its performance in reality. These shortcomings, which lead to increased charge carrier recombination, ${ }^{4,5}$ have been addressed by nanostructuring, ${ }^{6}$ by constructing hierarchical assemblies, ${ }^{7}$ by doping (e.g., with $\mathrm{Sn},{ }^{8-10} \mathrm{Si}^{11}{ }^{11} \mathrm{Mo},{ }^{12} \mathrm{Cr},{ }^{12} \mathrm{Pt},{ }^{13}$ and $\left.\mathrm{Ti}^{14-16}\right)$, and through the introduction of under- and overlayers at the back contact $^{17,18}$ and on top of the photoanodes, respectively. $\mathrm{Ti}^{19}{ }^{19} \mathrm{Si}^{14,20} \mathrm{Sn},{ }^{8,10,21}$ and $\mathrm{Pt}^{13,22}$ turned out to be the most effective dopants; however, minor improvements were also reported for hematite doped with $\mathrm{Mo},{ }^{12} \mathrm{Mg},{ }^{23} \mathrm{Ta}^{24} \mathrm{Nb},{ }^{23,25}$
$\mathrm{Zn}^{26}$ and $\mathrm{Ge}^{27}$ The introduction of heterojunctions has been proven to enhance the photoresponse for multiple reasons. Charge carriers may be transported in a cascade $\mathrm{e}^{-} / \mathrm{h}^{+}$transfer thanks to differently aligned valence and conduction bands in heterojunction engineered photoanodes. Such a system was reported for $\mathrm{Fe}_{2} \mathrm{O}_{3}-\mathrm{Fe}_{2} \mathrm{TiO}_{5}$. ${ }^{28}$ Another reason might be that hematite is completely transformed into another phase, for example, through high-temperature annealing, as described for a $\mathrm{WO}_{3}-\mathrm{Fe}_{2} \mathrm{WO}_{6}$ photoanode. ${ }^{29}$ Charge transport was further reported to be promoted by the introduction of thin layers at the hematite-F: $\mathrm{SnO}_{2}$ contact. In this case, the beneficial effects depend on the type of the layer. Whereas a $\mathrm{SiO}_{x}$ coating indirectly leads to improved morphology by acting as a seeding layer for the subsequently deposited hematite layer, ${ }^{30}$ the role of $\mathrm{Nb}_{2} \mathrm{O}_{5}$ underlayers is attributed to a "hole-mirror" effect and hence inhibits recombination. ${ }^{31}$ Moreover, such ultrathin (1-2 $\mathrm{nm}$ ) underlayers enable $\mathrm{n} / \mathrm{p}$-type ${ }^{32}$ doping at the interfaces upon annealing, comparable to $\mathrm{Sn}$ doping at the hematite$\mathrm{F}: \mathrm{SnO}_{2}$ interface detected after high-temperature treatments, thus improving charge transfer. ${ }^{33}$ Improvements in conductivity

Received: May 29, 2017

Accepted: July 25, 2017

Published: August 15, 2017 
regarding hematite-based photoanodes were also achieved by "disorder engineering" upon annealing under reducing conditions. The photocurrent enhancement through hydrogen (plasma) reduction is highly dependent on the process parameters and intends to avoid the formation of $\mathrm{Fe}_{3} \mathrm{O}_{4}$ responsible for dramatic performance lowering. ${ }^{34}$ Wet chemical reduction with " $\mathrm{H}$ " sources also leads to a pronounced improvement of the performance, which is attributed to surface engineering of the hematite photoanode, underlining the importance to differentiate between beneficial surface and adverse bulk effects of reduced $\alpha-\mathrm{Fe}_{2} \mathrm{O}_{3}$ containing $\mathrm{Fe}^{2+}$ impurities. 35

Generally, hematite-based photoanodes show a rather high onset potential, attributed to intrinsic surface states, which pin the Fermi level and cause a fixed barrier height. Consequently, the degree of band bending, which in turn is positively correlated with $\mathrm{e}^{-} / \mathrm{h}^{+}$separation, is dictated by the density and energy distribution of surface states. ${ }^{36,37}$ Attempts to reduce the negative impacts of surface states and thus to lower the flat band potential $\left(E_{\mathrm{fb}}\right)$ include high-temperature annealing, ${ }^{16}$ long annealing times, ${ }^{38}$ or surface modifications with fluoride ${ }^{39}$ or zinc ions. ${ }^{40}$ Moreover, passivation of surface states was realized with ultrathin coatings of $\mathrm{Al}_{2} \mathrm{O}_{3}{ }^{17}$ and $\mathrm{Ga}_{2} \mathrm{O}_{3}{ }^{18}$

Oxygen evolution catalysts (OECs) in turn facilitate hole transfer to the electrolyte, whereas both effects, passivation of surface states and acceleration of hole transfer, lead to a cathodic shift in the onset potential. ${ }^{17}$ The activity of a cocatalyst depends also on the photoanode itself, that is, the interface states need to be considered. ${ }^{41}$ Additionally, the phase composition of the cocatalyst determines its functionality. A good example is represented by cobalt phosphate ("Co-Pi"), which is among the most studied oxygen evolution catalysts. Its role as a catalyst in hematite photoanodes has been debated for a long time. The enhancement in performance was assigned to an acceleration of water oxidation, whereas other researchers attributed the cathodic shift to an increase of the space charge layer width of the photoanode. ${ }^{42}$ Another study links the performance improvement to a catalytic effect, in which a $\mathrm{Co}(\mathrm{OH})_{2} / \mathrm{Co}_{3} \mathrm{O}_{4}$ layer on hematite accelerated water oxidation. ${ }^{43}$ These contradictory results stem from the fact that the function of the catalysts is presumably dependent on the nature of the photoanode underneath, that is, its porosity, donor density, surface quality, and consequently the energy distribution and density of surface states. Moreover, the preparation history of the cocatalyst itself and the resulting phase composition may determine whether or not such an overlayer acts in a truly catalytic manner as a water oxidation catalyst (acceleration of hole transfer to the solution), ${ }^{43}$ as an adaptive junction (electrolyte permeable electrocatalyst), ${ }^{44}$ as a passivation layer (removing surface recombination centers), 17,18 or as a $\mathrm{p} / \mathrm{n}$-type heterojunction ${ }^{45}$ attributed to desirable charge separation.

A plethora of studies have been conducted on various oxygen evolution catalysts (OECs). The "library" of solid OECs ranges from single materials, such as $\mathrm{Ni}$ (although only active when traces of Fe are present); ${ }^{46} \mathrm{Fe}-,{ }^{47} \mathrm{Co}-,{ }^{48,49}$ and $\mathrm{Mn}$ oxides; ${ }^{50-52}$ carbon nanotubes; ${ }^{53}$ and $\mathrm{IrO}_{2}{ }^{54}$ to binary compositions with $\mathrm{Ni}-\mathrm{Co},{ }^{55} \mathrm{Ni}-\mathrm{Fe},{ }^{56-58} \mathrm{Co}-\mathrm{Fe},{ }^{59}$ and composites thereof with gold $^{60}$ and reduced graphene oxide (rGO). ${ }^{61}$ Not surprisingly, multicomponent materials usually outperform single compounds thanks to synergistic effects. For example, electronegative $\mathrm{Au}$ facilitates the formation of active $\mathrm{Co}^{4+}$ sites ${ }^{46}$ and rGO enhances the conductivity. ${ }^{61}$ Similar effects are also reported for $\mathrm{Fe}-\mathrm{Ni}$ mixtures as a result of electronic interactions between the two metals, where $\mathrm{Ni}$ supports the formation of $\mathrm{Fe}^{4+}$, thus contributing to the activation of $\mathrm{Fe}$ in $\mathrm{Ni}-\mathrm{Fe}$ electrocatalysts. ${ }^{58,62}$ Generally, a trade-off between stability and activity is reported for noble metal oxides with respect to their porosity and degree of crystallinity. The least crystalline and most porous OEC was found to be the most active but also prone to dissolution, thereby decreasing the long-term stability. ${ }^{63}$

In this contribution, we present a hematite-titania photoanode covered with a catalyst fabricated by a simple spincoating process. The hematite-titania composite layer was prepared by liquid phase processing using preformed nanoparticles with defined size, crystallinity, and shape. The improved activity compared to that of bare hematite stems from the incorporation of $\mathrm{Ti}$, resulting in the formation of a $\mathrm{Fe}_{2} \mathrm{O}_{3}-\mathrm{Fe}_{2} \mathrm{TiO}_{5}$ heterojunction. ${ }^{64}$ The photoanode is further modified with an amorphous ternary $\mathrm{Fe}-\mathrm{Ni}$-based cocatalyst ${ }^{65,66}$ with nominal composition " $\mathrm{Fe}_{20} \mathrm{Ni}_{40} \mathrm{Cr}_{40} \mathrm{O}_{x}$ ", which was previously shown by Gerken et al. ${ }^{67}$ to be a promising material with respect to oxygen evolution characteristics. Most studies on OECs are conducted in the dark in the oxygen evolution potential range. However, we wanted to gain further insights into the interplay between photoanodes and catalysts; therefore, we studied our system at potentials (e.g., 0.8-1.1 $\mathrm{V}_{\mathrm{RHE}}$ ) at which photoanode materials are usually operated. Impedance spectroscopy measurements revealed that the reason for the drastic improvement of the performance upon adding the photocatalyst layer on top of the photoanode does not stem from accelerated hole transfer to the electrolyte but is due to the formation of a $\mathrm{p} / \mathrm{n}$-type junction at the photoanode-catalyst interface.

\section{RESULTS AND DISCUSSION}

Voltammetric and Efficiency Measurements. The performance of the hematite-titania photoanodes could be drastically improved after the addition of the overlayer with nominal composition " $\mathrm{Fe}_{20} \mathrm{Cr}_{40} \mathrm{Ni}_{40} \mathrm{O}_{x}$ ", as depicted by voltammetric measurements in Figure 1.

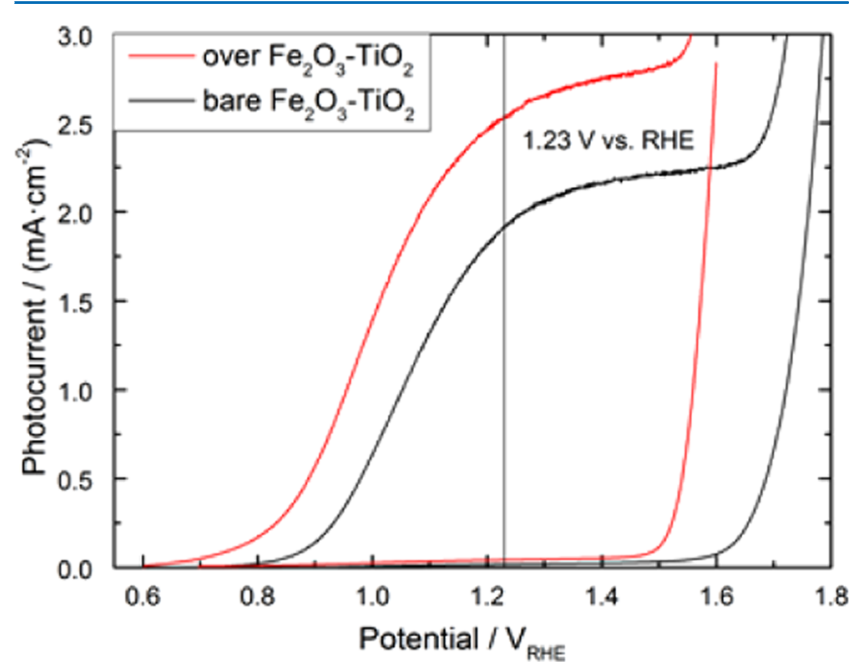

Figure 1. Photocurrent density of a $\mathrm{Fe}_{2} \mathrm{O}_{3}-\mathrm{TiO}_{2}$ photoanode before and after the addition of an amorphous overlayer with nominal composition " $\mathrm{Fe}_{20} \mathrm{Cr}_{40} \mathrm{Ni}_{40} \mathrm{O}_{x}$ " measured in $1 \mathrm{M} \mathrm{NaOH}$ under simulated AM $1.5 \mathrm{G}$ illumination $\left(100 \mathrm{~mW} / \mathrm{cm}^{2}\right)$. 
The observed changes, such as a cathodic shift in the range of about $80-100 \mathrm{mV}$ in the onset potential of the illuminated photoanodes and the increase in photocurrent by about $25 \%$ on average motivated us to perform a detailed study on the interplay of catalysts and photoactive layers. First, the amorphous overlayer comprises a surprisingly good stability as the photocurrent of the multilayer photoanode proved to be stable over the course of $24 \mathrm{~h}$ (Figure S4, Supporting Information (SI)). An increase was also observed with respect to the incident photon-to-current efficiency (IPCE) of the photoanodes. The overlayer improved the maximum IPCE value from ca. 25 to $40 \%$ between 300 and $330 \mathrm{~nm}$, as represented in Figure 2. The efficiency enhancement is less

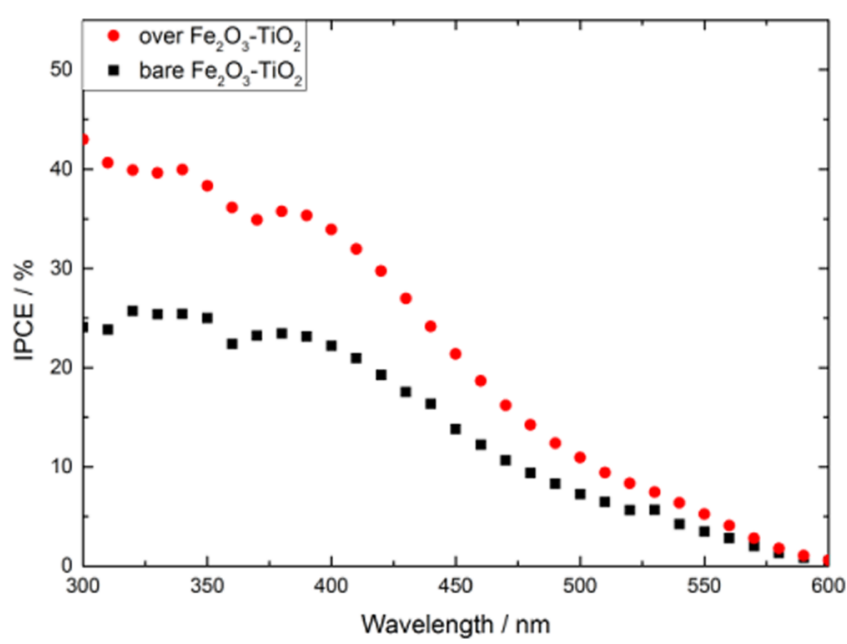

Figure 2. Incident photon-to-current efficiency of a bare $\mathrm{Fe}_{2} \mathrm{O}_{3}-\mathrm{TiO}_{2}$ and an overlayered $\mathrm{Fe}_{2} \mathrm{O}_{3}-\mathrm{TiO}_{2}$ photoanode, measured in $1 \mathrm{M} \mathrm{NaOH}$ under simulated AM 1.5 G illumination at a potential of $1.4 \mathrm{~V}_{\mathrm{RHE}}$.

pronounced in the visible range and accounts for about $10 \%$ improvement between 400 and $500 \mathrm{~nm}$, whereas at longer wavelengths, the enhancement is negligible. In addition, the catalyst layer shows no parasitic light absorption, which enables nearly full light penetration of the photoanode (Figure S5, SI).

The chopped light scan (Figure 3 ) reveals that the cathodic photocurrent decay is much higher for "over- $\mathrm{Fe}_{2} \mathrm{O}_{3}-\mathrm{TiO}_{2}$ " as compared to that for the bare photoanode at low potentials, whereas the trend reverses between 1.0 and $1.2 \mathrm{~V}_{\mathrm{RHE}}$. The cathodic photocurrent decays are of about the same magnitude in "bare- $\mathrm{Fe}_{2} \mathrm{O}_{3}-\mathrm{TiO}_{2}$ " over the entire voltage range. The cathodic transient photocurrent decay can be ascribed to three different recombination pathways: (i) accumulation of holes near the surface, (ii) accumulation of electrons in the bulk, or (iii) trapping of $\mathrm{e}^{-}$or $\mathrm{h}^{+}$at surface states. ${ }^{68}$ Backside illumination of the bare photoanode showed that the photocurrent is nearly identical or even slightly lower (Figure S1, SI). Therefore, accumulation of electrons in the bulk can be ruled out. In the work of Du et al. ${ }^{69}$ and Jang et al., ${ }^{70}$ the open circuit potentials in the dark are anodically shifted after depositing the $\mathrm{NiFeO}_{x}$ overlayer. The cathodic shift under illumination was understood to result from a greater photovoltage generation; thus, the increase in photocurrent was attributed to improved thermodynamics, rather than improved oxygen evolution kinetics. Moreover, the photocurrent enhancement throughout the entire potential range could point toward improved thermodynamic processes.

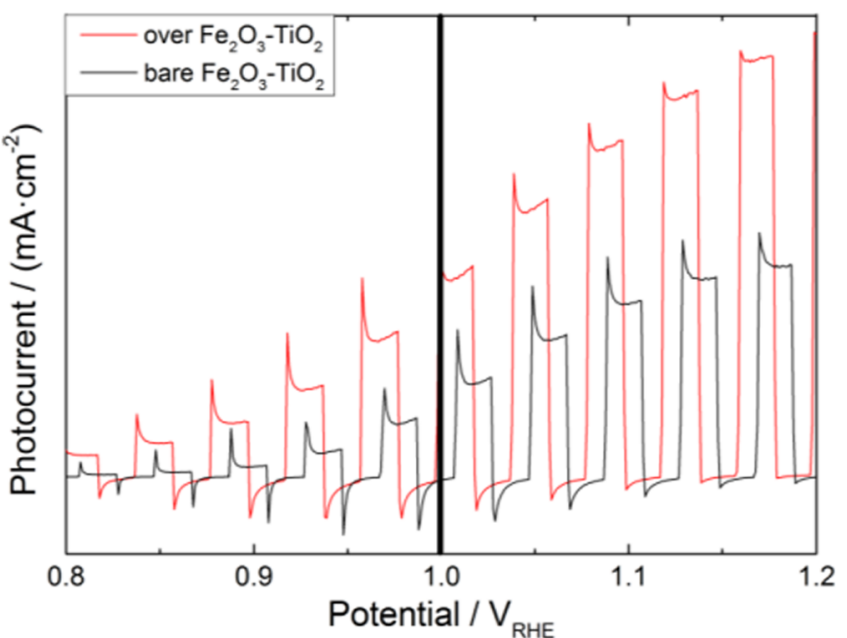

Figure 3. Photocurrent density of a $\mathrm{Fe}_{2} \mathrm{O}_{3}-\mathrm{TiO}_{2}$ photoanode before and after the addition of the overlayer measured in $1 \mathrm{M} \mathrm{NaOH}$ under simulated chopped AM $1.5 \mathrm{G}$ illumination $\left(100 \mathrm{~mW} / \mathrm{cm}^{2}\right)$.

Impedance Measurements. To unveil the role of the overlayer regarding charge transfer processes and capacitances, we performed impedance measurements (Figure 4). Because the surface of the photoanodes is sensitive to surface quality losses during impedance measurements, two similarly performing bare- $\mathrm{Fe}_{2} \mathrm{O}_{3}-\mathrm{TiO}_{2}$ photoanodes were used and only one was overlayered. First, we performed Mott-Schottky analysis (in the dark) to determine $E_{\mathrm{fb}}$ and the donor density $\left(N_{\mathrm{D}}\right)$. The Nyquist plots (Figure S9, SI) were fitted to a Randles circuit, and the potential-dependent capacitances were plotted according to the Mott-Schottky equation

$$
\frac{1}{C^{2}}=\frac{2}{e \varepsilon \varepsilon_{\mathrm{r}} N_{\mathrm{D}} A^{2}}\left(E-E_{\mathrm{fb}}-\frac{k T}{e}\right)
$$

where $N_{\mathrm{D}}$ is the donor density $\left(\mathrm{m}^{-3}\right), A$ is the electrode area $\left(\mathrm{m}^{2}\right), e$ is the elementary charge $\left(1.60 \times 10^{-19} \mathrm{C}\right), E_{\mathrm{fb}}$ is the flat band potential $(\mathrm{V}), \varepsilon$ is the vacuum permittivity $\left(8.85 \times 10^{-12}\right.$ $\left.\mathrm{F} \mathrm{m} \mathrm{m}^{-1}\right), \varepsilon_{\mathrm{r}}$ is the relative dielectric constant of hematite $\left(\varepsilon_{\mathrm{r}}=\right.$ $60){ }^{71} k$ is the Boltzmann constant $\left(1.38 \times 10^{-23} \mathrm{~J} \mathrm{~K}^{-1}\right)$, and $T$ is the absolute temperature (in $\mathrm{K}$ ). The slope is inversely proportional to $N_{\mathrm{D}}$, meaning that the larger the doping, the smaller the slope. The analysis of the slope for the bare- $\mathrm{Fe}_{2} \mathrm{O}_{3}-$ $\mathrm{TiO}_{2}$ photoanode shows that the donor density $\left(N_{\mathrm{D}}\right)$ is about $3.19 \times 10^{18} \mathrm{~cm}^{-3}$, whereas a donor density of about $2.12 \times 10^{18}$ $\mathrm{cm}^{-3}$ was measured for over- $\mathrm{Fe}_{2} \mathrm{O}_{3}-\mathrm{TiO}_{2}$ (Table S1, SI). The slightly lower value obtained for the overlayered photoanode suggests that the donor density dropped. From the intersect of $1 / C^{2}$ at the $x$-axis, $E_{\mathrm{fb}}$ can be obtained (Figure S8, Table S1, SI). The values for over- $\mathrm{Fe}_{2} \mathrm{O}_{3}-\mathrm{TiO}_{2}$ and bare- $\mathrm{Fe}_{2} \mathrm{O}_{3}-\mathrm{TiO}_{2}$ are 0.68 and $0.66 \mathrm{~V}$, respectively (Table $\mathrm{S} 1, \mathrm{SI}$ ). The standard deviation suggests that these two photoanodes do not significantly differ, indicating that the enhanced performance is not due to a shift in the flat band potential. Assuming that charge transfer occurs predominantly via surface states and due to the fact that the contribution of the Helmholtz capacitance $\left(C_{\mathrm{H}}\right)$ can be neglected, because $N_{\mathrm{D}}$ is well below $10^{20} \mathrm{~cm}^{-3}$, the circuit shown in Figure S10 (SI) was used and proved to be a good estimation for the surface state capacitance $\left(C_{\mathrm{ss}}\right)$, the bulk capacitance $\left(C_{\text {bulk }}\right)$, the surface charge transfer resistance $\left(R_{\mathrm{ct}, \mathrm{ss}}\right)$, and the trapping resistance $\left(R_{\text {trapping }}\right){ }^{68,72}$ 

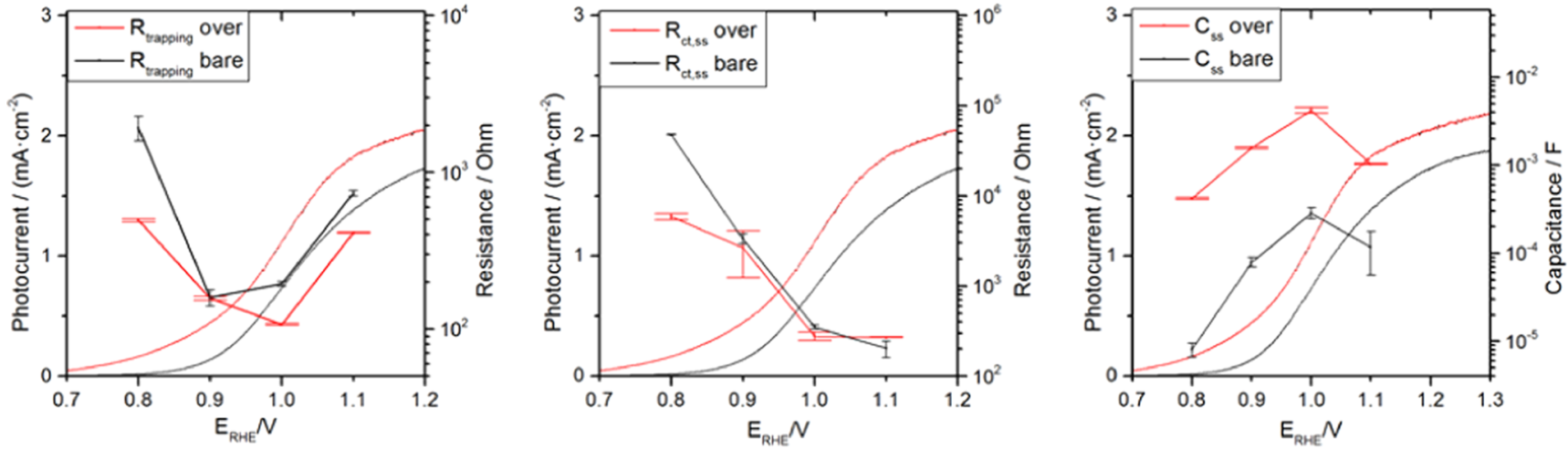

Figure 4. Resistances and capacitances associated with charge trapping $\left(R_{\text {trapping }}\right)$ and transfer $\left(R_{\mathrm{ct}, \mathrm{ss}}, C_{\mathrm{ss}}\right)$ at different applied potentials for the bare and the overlayered photoanode as obtained upon fitting the respective Nyquist plots (Figures S11 and S12, SI) to the equivalent circuit (EC) shown in Figure S10, SI. Resistance and capacitance values obtained from fitting are listed in Tables S2 and S3, SI. The measurements were performed in $1 \mathrm{M} \mathrm{NaOH}$ under simulated AM $1.5 \mathrm{G}$ illumination. Error bars stem from the goodness of the fittings. Note: $\mathrm{The}$ measured $\mathrm{Fe}_{2} \mathrm{O}_{3}-$ $\mathrm{TiO}_{2}$ photoanode exhibited a slightly lower performance as compared to that of the photoanode shown in Figures $1-3$.

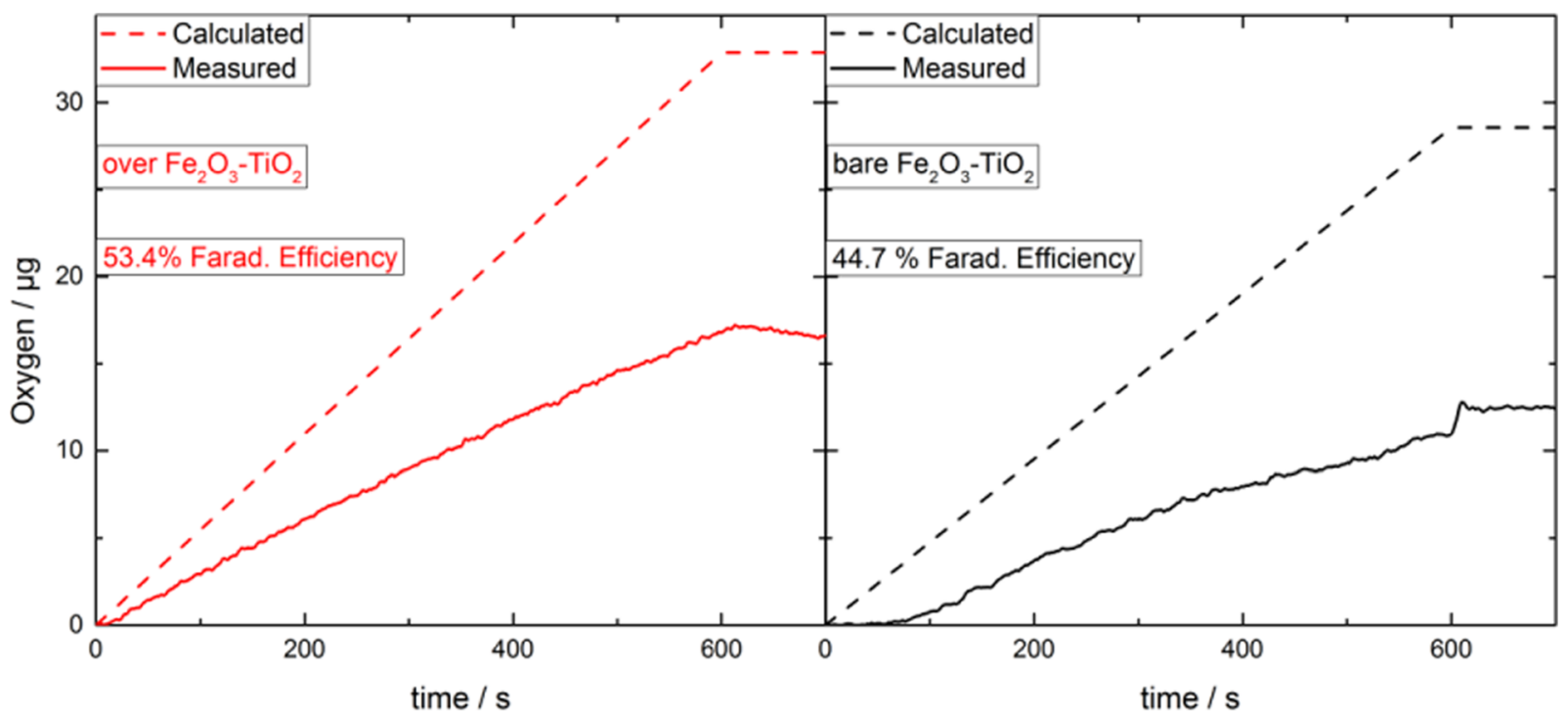

Figure 5. Oxygen evolution measurements of a bare $\mathrm{Fe}_{2} \mathrm{O}_{3}-\mathrm{TiO}_{2}$ (right) and an overlayered $\mathrm{Fe}_{2} \mathrm{O}_{3}-\mathrm{TiO}_{2}$ photoanode (left) performed in $1 \mathrm{M}$ $\mathrm{NaOH}$ under simulated AM $1.5 \mathrm{G}$ illumination at a potential of $1.23 \mathrm{~V}_{\mathrm{RHE}}$.

Impedance measurements of the illuminated samples were performed in the potential range between 0.8 and $1.1 \mathrm{~V}_{\mathrm{RHE}}$. As expected, the bulk capacitance $\left(C_{\text {bulk }}\right)$ is not significantly influenced by the addition of the overlayer (Figure S15, SI). The similar $R_{\mathrm{ct}, \mathrm{ss}}$ value for both photoanodes (Figure 4) proposes that the charge transfer to the aqueous electrolyte is not improved by the overlayer. However, the $C_{\mathrm{ss}}$ value for over$\mathrm{Fe}_{2} \mathrm{O}_{3}-\mathrm{TiO}_{2}$ is substantially higher, namely, by approximately 1 order of magnitude compared to that for bare- $\mathrm{Fe}_{2} \mathrm{O}_{3}-\mathrm{TiO}_{2}$. Furthermore, the peak of $C_{\mathrm{ss}}$ is consistent with the inflection potential in the photocurrent curve. If the " $\mathrm{Fe}_{20} \mathrm{Cr}_{40} \mathrm{Ni}_{40} \mathrm{O}_{x}$ " layer acted as a true water oxidation catalyst, a lowering of $C_{\mathrm{ss}}$ would have been expected. ${ }^{43}$ Furthermore, $C_{\mathrm{ss}}$ is much higher over the entire potential range, which suggests that the photocurrent improvement stems mainly from the capability of the catalyst to store holes, representing a thermodynamic improvement.

$\mathrm{NiFeO}_{x}$-hematite heterostructures are assumed to form a $\mathrm{p} /$ n-type junction, as stated by Zandi et al., ${ }^{73}$ owing to the improved turn-on photovoltage as a result of the addition of the catalyst. ${ }^{70}$ Moreover, in our case, $R_{\text {trapping }}$ is slightly lower after coating the photoanode. This supports the observation made by $\mathrm{Du}$ et al. ${ }^{69}$ that $\mathrm{FeNiO}_{x}$-type overlayers on hematite are able to reduce Fermi level pinning. A lower $R_{\text {trapping }}$ value indicates that the catalyst thus extracts holes located in the traps created by surface states in the hematite-titania layer. Induced by the addition of titania, these traps are presumably located few hundred millivolts more negative than the valence band position of the hematite-titania composite. ${ }^{64}$

Microstructural and Composition Effects. Impedance measurements performed by Morales-Guio et al. ${ }^{74}$ on samples with $\mathrm{Fe} / \mathrm{Ni}=70: 30$ revealed a $C_{\mathrm{ss}}$ and $R_{\mathrm{ct}, \mathrm{ss}}$ value decrease upon photoelectrodeposition on hematite, pointing toward an acceleration of water oxidation kinetics. In our case, the $\mathrm{Fe}-$ Ni-type catalyst additionally contains chromium $(\mathrm{Fe} / \mathrm{Ni} / \mathrm{Cr}=$ 58:24:40, Table S4, SI), which is leaching out upon electrolysis at least from the outermost surface as confirmed by X-ray photoelectron spectroscopy (XPS) and secondary-ion mass spectrometry (SIMS) analyses (Figures S7, S13, and S14, SI), as expected when looking at Pourbaix diagrams. ${ }^{75}$ The removal of chromium from the top of the catalyst layer increases the surface roughness ${ }^{67}$ and may promote permeability of the 
catalyst by the electrolyte, thereby reducing the potential drop at the catalyst-electrolyte interface. ${ }^{44}$ The loss of $\mathrm{Cr}$ and the change in intensity of the $\mathrm{Ni} 2 \mathrm{p}$ photopeaks (XPS) further suggest that the catalyst layer rearranges upon polarization (Figure S7, SI). In a study by Gerken et al., the composition $\mathrm{Fe}_{20} \mathrm{Ni}_{40} \mathrm{Cr}_{40} \mathrm{O}_{x}$ was among those with the highest roughness factors. ${ }^{67}$ Only earth alkaline metal-containing compositions outperformed the composition $\mathrm{Fe}_{20} \mathrm{Ni}_{40} \mathrm{Cr}_{40} \mathrm{O}_{x}$ in terms of roughness factor according to a screening of different catalysts. ${ }^{67}$ Compared to that in a dense catalyst, no potential drop across the Helmholtz layer is expected to occur because the electronic charge is compensated by the coupled ion motion in the electrolyte. ${ }^{44}$

Oxygen evolution measurements (Figure 5) were performed to study the effect of the catalyst on the Faradaic efficiency. The Faradaic efficiency is measured with respect to the photocurrent, which directly allows us to gain further insights into the ability of the catalyst to evolve oxygen. Indeed, the Faradaic efficiency rises by about $9 \%$, pointing toward the ability of the catalyst to improve the oxygen evolution kinetics. Although the main improvement in photocurrent is linked to thermodynamic effects, as found by impedance spectroscopy, one has to keep in mind that the oxygen evolution was measured at a potential of $1.23 \mathrm{~V}_{\mathrm{RHE}}$, whereas the impedance analysis was performed at potentials between 0.8 and $1.1 \mathrm{~V}_{\mathrm{RHE}}$. The more the anodic potential, the stronger the oxidative power of holes becomes. Thus, effects such as partial charge transfer activation in the "Ni-O-Fe" bond facilitates stabilization of redox shuttles, which are supposed to drive the water oxidation. ${ }^{58,76}$ Regarding the implementation of such a photoanode into a tandem cell, the observations made at low potential are important because the operating point for tandem cells, depending on the band gap and band position, usually lies in the lower potential range. $^{74}$

\section{CONCLUSIONS}

The addition of a NiFe-type catalyst layer significantly raised the photocurrent over the entire voltage range, and a minor cathodic shift for the onset potential of about $80-100 \mathrm{mV}$ was observed. The photocurrents plateau above $1.3 \mathrm{~V}_{\mathrm{RHE}}$ and increased from ca. 1.9 to $2.5 \mathrm{~mA} / \mathrm{cm}^{2}$ at $1.23 \mathrm{~V}_{\mathrm{RHE}}$ after the addition of the catalyst layer. The cathodic current transient revealed the charge decay to be higher in the lower potential range $\left(0.8-1.0 \mathrm{~V}_{\mathrm{RHE}}\right)$, but only with the deposited overlayer, pointing toward the ability of the catalyst to hold charges. Indeed, impedance analysis showed that the surface state capacitance $\left(C_{\mathrm{ss}}\right)$ increased by one order of magnitude, whereas the charge transfer resistance $\left(R_{\mathrm{ct}, \mathrm{ss}}\right)$ remained unchanged when compared to that of the bare photoanode, thus confirming the hole storage capability of the catalyst layer. Moreover, the slightly reduced trapping resistance $\left(R_{\text {trapping }}\right)$ indicates that the catalyst layer is able to efficiently extract holes from surface states of the hematite-titania photoanode. On the other hand, oxygen measurements at $1.23 \mathrm{~V}_{\mathrm{RHE}}$ unveiled a slightly better Faradaic efficiency after addition of the catalyst, possibly as a result of the higher applied potential compared to that in the impedance analysis. Thus, at higher potentials the oxidative power of the holes increases and the catalyst becomes more active toward OER.

Amorphous materials are prone to destabilization, which could be confirmed here after prolonged $(48 \mathrm{~h})$ electrolysis. Accordingly, it remains a trade-off to simultaneously optimize both functionalities, namely, high activity and long-term stability. At the same time, we need to emphasize that the conclusions drawn from our work cannot simply be extended to other photoactive materials because the functionality of the catalyst layer is not only dependent on its composition, porosity, and crystallinity but also on the photoactive material underneath. Nevertheless, our study provides a basis for understanding the interplay between photoactive materials and catalysts and may pave the way for further improvements, for example, by the addition of a catalyst that accelerates hole transfer to the solution at lower potentials.

\section{EXPERIMENTAL SECTION}

Preparation of Amorphous Iron Oxide Nanoparticles. A microwave-assisted nonaqueous sol-gel route using $\mathrm{Fe}$ $(\mathrm{acac})_{3}$ (Sigma-Aldrich, $\geq 99.9 \%$ ), benzyl alcohol (SigmaAldrich, anhydrous, 99.8\%), and 1,3-propanediol (Alfa Aesar, $99 \%)$ was pursued as described in detail in ref 64 . The particle size ranges from 2 to $4 \mathrm{~nm}$ according to a previously performed transmission electron microscopy analysis. ${ }^{77}$ The amorphous iron oxide nanoparticles were dispersed in methanol at a concentration of approximately $65 \mathrm{mg} \mathrm{mL}^{-1}$.

Preparation of Titania Nanoparticles. The approximately $4 \mathrm{~nm}$ sized anatase titania nanoparticles were obtained using an oil bath synthesis. First, $\mathrm{TiCl}_{4}$ (Aldrich, 99.9\%) was dissolved in ethanol (Aldrich, $\geq 99.8 \%$ ), followed by addition of $\mathrm{BnOH}$ and 1,3-propanediol. A detailed synthesis procedure can be found in ref 64 .

Preparation of Nanostructured Hematite-Titania Photoanodes. Hematite-titania photoanodes were prepared by spin-coating mixed dispersions of amorphous iron oxide and anatase $\mathrm{TiO}_{2}$ nanoparticles on $\mathrm{F} / \mathrm{SnO}_{2}$ substrates $(7 \Omega / \mathrm{sq}$, Solaronix) with a $\mathrm{TiO}_{2}$ content of $\mathrm{Ti}(\mathrm{mol} \%) /[\mathrm{Ti}(\mathrm{mol} \%)+$ $\mathrm{Fe}(\mathrm{mol} \%)]=12 \%$. The films were annealed at $750{ }^{\circ} \mathrm{C}$ at a ramp of $20^{\circ} \mathrm{C} / \mathrm{min}$ in a pure oxygen atmosphere for $20 \mathrm{~min}$, followed by quenching in air. Energy-dispersive X-ray spectroscopy (EDX) analysis showed that the atomic percentage of $\mathrm{Ti}$ was $10.13 \%$ (Figure S16, SI). The hematite-titania photoanode without overlayer is abbreviated as bare- $\mathrm{Fe}_{2} \mathrm{O}_{3}-$ $\mathrm{TiO}_{2}$.

Preparation of the Hematite-Titania- $\mathrm{Fe}_{20} \mathrm{Cr}_{40} \mathrm{Ni}_{40} \mathrm{O}_{x}$ Photoanodes. The preparation of the overlayers was inspired by the deposition process used by Smith et al., ${ }^{66}$ however performed in a slightly different way: 2-ethylhexanoates of $\mathrm{Fe}^{3+}$ (50 wt \% in mineral spirits, Alfa Aesar, $214 \mu \mathrm{L}$ ), $\mathrm{Cr}^{3+}$ (70 wt \% in mineral spirits, $\mathrm{ABCR}$ Chemicals, $273 \mu \mathrm{L}$ ), and $\mathrm{Ni}^{2+}(78 \mathrm{wt}$ $\%$ in 2-ethylhexanoic acid, ABCR Chemicals, $184 \mu \mathrm{L}$ ) were dissolved in $7.6 \mathrm{~mL}$ of $n$-heptane (ACROS, $>99 \%$, extra dry), stirred for $2 \mathrm{~h}$, and then centrifuged at $4000 \mathrm{rpm}$ for $15 \mathrm{~min}$ to remove agglomerates prior to deposition. The solution was spin-coated on a hematite-titania photoanode at $3000 \mathrm{rpm}$ for $60 \mathrm{~s}$. The overlayered photoanode was then dried on a hot plate at $150{ }^{\circ} \mathrm{C}$ for $1 \mathrm{~h}$. Infrared spectroscopy was employed to follow the thermochemical decomposition of the precursors. After the heat treatment, the $\mathrm{C}-\mathrm{H}\left(2800-3000 \mathrm{~cm}^{-1}\right)$ and $\mathrm{C}=\mathrm{O}\left(\sim 1680 \mathrm{~cm}^{-1}\right)$ vibrations disappeared, as shown for $\mathrm{KBr}$ disks coated with the precursor solution (Figure S6, SI). The thicknesses of the hematite-titania films and the OEC layers were in the range of $180-200 \mathrm{~nm}$ and about $100 \mathrm{~nm}$, respectively, as determined by cross-sectional scanning electron microscopy (SEM) analysis (Figure S2, SI). However, after electrolysis, the thickness of the overlayer decreased drastically to $<20 \mathrm{~nm}$, as estimated by cross-sectional SEM analysis (Figure S3, SI). It is assumed that the catalyst covered the 
entire surface of the porous photoanode. Elemental analysis of the precursor solution used for the deposited catalysts revealed a $\mathrm{Fe} / \mathrm{Ni} / \mathrm{Cr}$ atomic ratio of about 58:24:40 (Table S4, SI). The abbreviation over- $\mathrm{Fe}_{2} \mathrm{O}_{3}-\mathrm{TiO}_{2}$ stands for the hematite-titania photoanode overlayered with such a $\mathrm{FeNiCrO}_{x}$ layer.

Optical, Structural, and Morphological Film Characterization and Photoelectrochemical Measurements. Xray photoelectron spectra (XPS) were recorded on a Sigma 2 spectrometer (Thermo scientific) using a nonmonochromatic Al $\mathrm{K} \alpha \mathrm{X}$-ray source, where the binding energy was calibrated taking C $1 \mathrm{~s}=284.8 \mathrm{eV}$. EDX was performed on a Hitachi SU70 scanning electron microscope operated at an acceleration voltage of $15 \mathrm{kV}$ (Schottky-type field emission gun) and equipped with a X-Max 80 detector (Oxford Instruments). SEM analysis was performed on a Carl Zeiss LEO 1530 microscope equipped with a field emission gun operating at 3 $\mathrm{kV}$. For the cross-sectional images, the photoanode was cut in the middle with a diamond knife. Fourier transform infrared (FT-IR) spectroscopy was performed on a Spectrum 100 FTIR spectrometer using a $\mathrm{KBr}$ pellet with the following acquisition parameters: range 4000 to $600 \mathrm{~cm}^{-1}$, resolution of $4.00 \mathrm{~cm}^{-1}$, scan speed of $0.2 \mathrm{~cm} / \mathrm{s}$, and the number of scans was 30. UV-vis spectra were obtained using a JASCO V-660 spectrophotometer with an ILN-725 integrating sphere accessory. Because the same sample was used for all measurements, no background correction was made. The acquisition parameters were as follows: scan speed $400 \mathrm{~nm} /$ min, change source at $340 \mathrm{~nm}$, light source D2/WI, filter exchange step, correction baseline, vertical axis $\% T$, and data interval $0.5 \mathrm{~nm}$. Photoelectrochemical (PEC) measurements were carried out with a VMP3 BioLogic potentiostat. Simulated AM 1.5 G solar irradiation was provided by an Oriel solar simulator equipped with a $300 \mathrm{~W}$ Xe lamp and fitted with an AM 1.5 G filter. Light intensity was measured with a calibrated reference cell (Oriel, $91150 \mathrm{~V}$ ) and adjusted to $100 \mathrm{~mW} / \mathrm{cm}^{2}$ with a neutral density filter (Newport, FS-ND). The surface area illuminated on the photoelectrode was $0.28 \mathrm{~cm}^{2}$. Measurements were performed at a scan rate of $10 \mathrm{mV} / \mathrm{s}$. The potential was transformed to the reversible hydrogen electrode (RHE) with the following equation

$$
E\left(\mathrm{~V}_{\mathrm{RHE}}\right)=E\left(\mathrm{~V}_{\mathrm{Ag} / \mathrm{AgCl}}\right)+0.0591 \mathrm{pH}+0.197
$$

The $\mathrm{pH}$ of the electrolyte $(1 \mathrm{M} \mathrm{NaOH})$ was assumed to be 13.6, and the potential of the $\mathrm{Ag} / \mathrm{AgCl} / \mathrm{KCl} /$ sat. $\mathrm{KCl}$ reference electrode (Radiometer Analytical) was $0.197 \mathrm{~V}$. Incident photon-to-current efficiency (IPCE) measurements were carried out in $1 \mathrm{M} \mathrm{NaOH}$ at $0.4 \mathrm{~V}$ versus $\mathrm{Ag} / \mathrm{AgCl} /$ sat. $\mathrm{KCl}$ using a $1000 \mathrm{~W}$ Xe lamp coupled with a monochromator. A Si photodetector (Optronic Laboratories) was used to measure irradiance at each selected wavelength. IPCE was calculated with the following equation

$$
\operatorname{IPCE}(\%)=\frac{1240(\mathrm{~V} \cdot \mathrm{nm}) \cdot I_{\mathrm{ph}}(\mathrm{A})}{\lambda(\mathrm{nm}) \cdot P_{\text {light }}(\mathrm{W})} \times 100
$$

(Photo)electrochemical impedance spectroscopy (EIS) data was acquired with an $\mathrm{AC}$ perturbation of $10 \mathrm{mV}$ in amplitude and in the $100 \mathrm{mHz}$ to $1 \mathrm{MHz}$ frequency range, both in the dark and under illumination and under selected direct current potentiostatic conditions $\left(0.7-1.4 \mathrm{~V}_{\mathrm{RHE}}\right)$. Nyquist plots (imaginary vs real components of impedance, $-Z_{\mathrm{Im}}$ vs $Z_{\mathrm{Re}}$ ) were fitted to the corresponding equivalent circuits using ECLab software (Bio-Logic, v10.44). Fitted resistances and capacitances are referred to the electrode real surface, and a roughness factor of ca. 20 for mesoporous hematite is taken according to Kay et al. ${ }^{11}$ Error bars stem from the goodness of the fittings. Oxygen was detected quantitatively using a PyroScience fluorescence based oxygen sensor (OXB430-OI). The cell was filled with $1 \mathrm{M} \mathrm{NaOH}$ and degassed with argon prior to the measurements. The oxygen probe was inserted through a rubber septum, and continuous $\mathrm{O}_{2}$ readings were conducted at $1 \mathrm{~s}$ interval throughout the experiment. The probe was calibrated using 2 points (argon: $0 \% \mathrm{O}_{2}$ and air: 20.9\% $\mathrm{O}_{2}$ ) with an error of $5 \%$ on the reading. Prior to the experiment, the baseline was measured for $30 \mathrm{~min}$, followed by $10 \mathrm{~min}$ illumination with simulated AM $1.5 \mathrm{G}$ irradiation $(100 \mathrm{~mW} /$ $\mathrm{cm}^{2}$ ) at $1.23 \mathrm{~V}_{\mathrm{RHE}}$. Oxygen leakage was subtracted by measuring the leakage rate before and after the measurement. Secondary ion mass spectrometry (SIMS) with high depth resolution was performed by means of a time-of-flight-mass spectrometer from Tofwerk AG (model C-TOF) integrated on a focused ion beam instrument (Lyra FIB) from Tescan. Lowimpact-energy $(5 \mathrm{keV}) \mathrm{Ga}^{+}$ions with a primary ion current of $180 \mathrm{pA}$ were used for the elemental separation of the different layers.

\section{ASSOCIATED CONTENT}

\section{S Supporting Information}

The Supporting Information is available free of charge on the ACS Publications website at DOI: 10.1021/acsomega.7b00696.

Additional photoelectrochemical measurements; SEM, XPS and transmittance measurements of films; MottSchottky plots; Nyquist plots; SIMS depths profiles; resistance data and elemental analyses (PDF)

\section{AUTHOR INFORMATION}

\section{Corresponding Author}

*E-mail: markus.niederberger@mat.ethz.ch.

ORCID

Markus Niederberger: 0000-0001-6058-1183

\section{Author Contributions}

The manuscript was written through contributions of all authors. All authors have given approval to the final version of the manuscript.

\section{Funding}

We gratefully thank ETH Zurich, the Polish-Swiss Research Programme (PSP-132/2010, hybrid semiconducting materials for solar energy conversion), and SOLAROGENIX (NMP4SL-2012-310333) for financial support.

\section{Notes}

The authors declare no competing financial interest.

\section{ACKNOWLEDGMENTS}

We gratefully acknowledge Dr. Guobo Zeng for performing XPS measurements and Dr. Martin Badertscher for conducting IR measurements. We further thank Dr. Malwina Staniuk for assistance with EDX measurements.

\section{REFERENCES}

(1) Maitra, U.; Lingampalli, S. R.; Rao, C. N. R. Artificial Photosynthesis and the Splitting of Water to Generate Hydrogen. Curr. Sci. 2014, 106, 518-527.

(2) Chen, Z.; Jaramillo, T. F.; Deutsch, T. G.; Kleiman-Shwarsctein, A.; Forman, A. J.; Gaillard, N.; Garland, R.; Takanabe, K.; Heske, C.; 
Sunkara, M.; McFarland, E. W.; Domen, K.; Miller, E. L.; Turner, J. A.; Dinh, H. N. Accelerating Materials Development for Photoelectrochemical Hydrogen Production: Standards for Methods, Definitions, and Reporting Protocols. J. Mater. Res. 2010, 25, 3-16.

(3) Liu, C.; Dasgupta, N. P.; Yang, P. Semiconductor Nanowires for Artificial Photosynthesis. Chem. Mater. 2014, 26, 415-422.

(4) Abrantes, L. M.; Peter, L. M. Transient Photocurrents at Passive Iron Electrodes. J. Electroanal. Chem. Interfacial Electrochem. 1983, 150, 593-601.

(5) Peter, L. M.; Li, J.; Peat, R. Surface Recombination at Semiconductor Electrodes: Part I. Transient and Steady-State Photocurrents. J. Electroanal. Chem. Interfacial Electrochem. 1984, $165,29-40$

(6) Osterloh, F. E. Inorganic Nanostructures for Photoelectrochemical and Photocatalytic Water Splitting. Chem. Soc. Rev. 2013, 42, 2294-2320.

(7) Yang, T.-Y.; Kang, H.-Y.; Jin, K.; Park, S.; Lee, J.-H.; Sim, U.; Jeong, H.-Y.; Joo, Y.-C.; Nam, K. T. An Iron Oxide Photoanode with Hierarchical Nanostructure for Efficient Water Oxidation. J. Mater. Chem. A 2014, 2, 2297-2305.

(8) Ling, Y.; Wang, G.; Wheeler, D. A.; Zhang, J. Z.; Li, Y. Sn-Doped Hematite Nanostructures for Photoelectrochemical Water Splitting. Nano Lett. 2011, 11, 2119-2125.

(9) Qin, D.-D.; Li, Y.-L.; Wang, T.; Li, Y.; Lu, X.-Q.; Gu, J.; Zhao, Y.X.; Song, Y.-M.; Tao, C.-L. Sn-Doped Hematite Films as Photoanodes for Efficient Photoelectrochemical Water Oxidation. J. Mater. Chem. A 2015, 3, 6751-6755.

(10) Gonçalves, R. H.; Leite, E. R. The Colloidal Nanocrystal Deposition Process: An Advanced Method to Prepare High Performance Hematite Photoanodes for Water Splitting. Energy Environ. Sci. 2014, 7, 2250-2254.

(11) Kay, A.; Cesar, I.; Grätzel, M. New Benchmark for Water Photooxidation by Nanostructured $\alpha-\mathrm{Fe}_{2} \mathrm{O}_{3}$ Films. J. Am. Chem. Soc. 2006, 128, 15714-15721.

(12) Kleiman-Shwarsctein, A.; Hu, Y.-S.; Forman, A. J.; Stucky, G. D.; McFarland, E. W. Electrodeposition of $\alpha-\mathrm{Fe}_{2} \mathrm{O}_{3}$ Doped with Mo or $\mathrm{Cr}$ as Photoanodes for Photocatalytic Water Splitting. J. Phys. Chem. C 2008, 112, 15900-15907.

(13) Kim, J. Y.; Magesh, G.; Youn, D. H.; Jang, J.-W.; Kubota, J.; Domen, K.; Lee, J. S. Single-Crystalline, Wormlike Hematite Photoanodes for Efficient Solar Water Splitting. Sci. Rep. 2013, 3, No. 2681.

(14) Glasscock, J. A.; Barnes, P. R. F.; Plumb, I. C.; Savvides, N. Enhancement of Photoelectrochemical Hydrogen Production from Hematite Thin Films by the Introduction of Ti and Si. J. Phys. Chem. C 2007, 111, 16477-16488.

(15) Shen, S.; Kronawitter, C. X.; Wheeler, D. A.; Guo, P.; Lindley, S. A.; Jiang, J.; Zhang, J. Z.; Guo, L.; Mao, S. S. Physical and Photoelectrochemical Characterization of Ti-Doped Hematite Photoanodes Prepared by Solution Growth. J. Mater. Chem. A 2013, 1, $14498-14506$.

(16) Kronawitter, C. X.; Zegkinoglou, I.; Shen, S. H.; Liao, P.; Cho, I. S.; Zandi, O.; Liu, Y. S.; Lashgari, K.; Westin, G.; Guo, J. H.; Himpsel, F. J.; Carter, E. A.; Zheng, X. L.; Hamann, T. W.; Koel, B. E.; Mao, S. S.; Vayssieres, L. Titanium Incorporation into Hematite Photoelectrodes: Theoretical Considerations and Experimental Observations. Energy Environ. Sci. 2014, 7, 3100-3121.

(17) Le Formal, F.; Tetreault, N.; Cornuz, M.; Moehl, T.; Grätzel, M.; Sivula, K. Passivating Surface States on Water Splitting Hematite Photoanodes with Alumina Overlayers. Chem. Sci. 2011, 2, 737-743.

(18) Hisatomi, T.; Le Formal, F.; Cornuz, M.; Brillet, J.; Tetreault, N.; Sivula, K.; Grätzel, M. Cathodic Shift in Onset Potential of Solar Oxygen Evolution on Hematite by 13-Group Oxide Overlayers. Energy Environ. Sci. 2011, 4, 2512-2515.

(19) Wang, G.; Ling, Y.; Wheeler, D. A.; George, K. E. N.; Horsley, K.; Heske, C.; Zhang, J. Z.; Li, Y. Facile Synthesis of Highly Photoactive $\alpha$ - $\mathrm{Fe}_{2} \mathrm{O}_{3}$-Based Films for Water Oxidation. Nano Lett. 2011, 11, 3503-3509.
(20) Cesar, I.; Sivula, K.; Kay, A.; Zboril, R.; Grätzel, M. Influence of Feature Size, Film Thickness, and Silicon Doping on the Performance of Nanostructured Hematite Photoanodes for Solar Water Splitting. J. Phys. Chem. C 2009, 113, 772-782.

(21) Zong, X.; Thaweesak, S.; Xu, H.; Xing, Z.; Zou, J.; Lu, G.; Wang, L. A Scalable Colloidal Approach to Prepare Hematite Films for Efficient Solar Water Splitting. Phys. Chem. Chem. Phys. 2013, 15, 12314-12321.

(22) Hu, Y.-S.; Kleiman-Shwarsctein, A.; Forman, A. J.; Hazen, D.; Park, J.-N.; McFarland, E. W. Pt-Doped $\alpha$ - $\mathrm{Fe}_{2} \mathrm{O}_{3}$ Thin Films Active for Photoelectrochemical Water Splitting. Chem. Mater. 2008, 20, 38033805.

(23) Leygraf, C.; Hendewerk, M.; Somorjai, G. A. Photocatalytic Production of Hydrogen from Water by a p-and n-type Polycrystalline Iron Oxide Assembly. J. Phys. Chem. 1982, 86, 4484-4485.

(24) Aroutiounian, V. M.; Arakelyan, V. M.; Shahnazaryan, G. E.; Stepanyan, G. M.; Turner, J. A.; Khaselev, O. Investigation of Ceramic $\mathrm{Fe}_{2} \mathrm{O}_{3}\langle\mathrm{Ta}\rangle$ Photoelectrodes for Solar Energy Photoelectrochemical Converters. Int. J. Hydrogen Energy 2002, 27, 33-38.

(25) Aroutiounian, V. M.; Arakelyan, V. M.; Shahnazaryan, G. E.; Stepanyan, G. M.; Khachaturyan, E. A.; Wang, H.; Turner, J. A. Photoelectrochemistry of Semiconductor Electrodes Made of Solid Solutions in the System $\mathrm{Fe}_{2} \mathrm{O}_{3}-\mathrm{Nb}_{2} \mathrm{O}_{5}$. Sol. Energy 2006, 80, 10981111.

(26) Ingler, W. B., Jr.; Baltrus, J. P.; Khan, S. U. M. Photoresponse of p-Type Zinc-Doped Iron(III) Oxide Thin Films. J. Am. Chem. Soc. 2004, 126, 10238-10239.

(27) Kennedy, J. H.; Anderman, M.; Shinar, R. Photoactivity of Polycrystalline $\alpha-\mathrm{Fe}_{2} \mathrm{O}_{3}$ Electrodes Doped with Group IVA Elements. J. Electrochem. Soc. 1981, 128, 2371-2373.

(28) Deng, J.; Lv, X.; Liu, J.; Zhang, H.; Nie, K.; Hong, C.; Wang, J.; Sun, X.; Zhong, J.; Lee, S.-T. Thin-Layer $\mathrm{Fe}_{2} \mathrm{TiO}_{5}$ on Hematite for Efficient Solar Water Oxidation. ACS Nano 2015, 9, 5348-5356.

(29) Solarska, R.; Bieńkowski, K.; Królikowska, A.; Dolata, M.; Augustyński, J. Nanoporous $\mathrm{WO}_{3}-\mathrm{Fe}_{2} \mathrm{O}_{3}$ Films; Structural and PhotoElectrochemical Characterization. Funct. Mater. Lett. 2014, 07, No. 1440006.

(30) Le Formal, F.; Grätzel, M.; Sivula, K. Controlling Photoactivity in Ultrathin Hematite Films for Solar Water-Splitting. Adv. Funct. Mater. 2010, 20, 1099-1107.

(31) Hisatomi, T.; Dotan, H.; Stefik, M.; Sivula, K.; Rothschild, A.; Grätzel, M.; Mathews, N. Enhancement in the Performance of Ultrathin Hematite Photoanode for Water Splitting by an Oxide Underlayer. Adv. Mater. 2012, 24, 2699-2702.

(32) Steier, L.; Herraiz-Cardona, I.; Gimenez, S.; Fabregat-Santiago, F.; Bisquert, J.; Tilley, S. D.; Grätzel, M. Understanding the Role of Underlayers and Overlayers in Thin Film Hematite Photoanodes. Adv. Funct. Mater. 2014, 24, 7681-7688.

(33) Gonçalves, R. H.; Lima, B. H. R; Leite, E. R. Magnetite Colloidal Nanocrystals: A Facile Pathway To Prepare Mesoporous Hematite Thin Films for Photoelectrochemical Water Splitting. J. Am. Chem. Soc. 2011, 133, 6012-6019.

(34) Mettenbörger, A.; Singh, T.; Singh, A. P.; Järvi, T. T.; Moseler, M.; Valldor, M.; Mathur, S. Plasma-Chemical Reduction of Iron Oxide Photoanodes for Efficient Solar Hydrogen Production. Int. J. Hydrogen Energy 2014, 39, 4828-4835.

(35) Li, M.; Deng, J.; Pu, A.; Zhang, P.; Zhang, H.; Gao, J.; Hao, Y.; Zhong, J.; Sun, X. Hydrogen-Treated Hematite Nanostructures with Low Onset Potential for Highly Efficient Solar Water Oxidation. J. Mater. Chem. A 2014, 2, 6727-6733.

(36) Bard, A. J.; Bocarsly, A. B.; Fan, F. R. F.; Walton, E. G.; Wrighton, M. S. The Concept of Fermi Level Pinning at Semiconductor/Liquid Junctions. Consequences for Energy Conversion Efficiency and Selection of Useful Solution Redox Couples in Solar Devices. J. Am. Chem. Soc. 1980, 102, 3671-3677.

(37) Lewerenz, H. J. Surface States and Fermi Level Pinning at Semiconductor/Electrolyte Junctions. J. Electroanal. Chem. 1993, 356, 121-143. 
(38) Iandolo, B.; Zhang, H.; Wickman, B.; Zoric, I.; Conibeer, G.; Hellman, A. Correlating Flat Band and Onset Potentials for Solar Water Splitting on Model Hematite Photoanodes. RSC Adv. 2015, 5, 61021-61030.

(39) Hu, Y.-S.; Kleiman-Shwarsctein, A.; Stucky, G. D.; McFarland, E. W. Improved Photoelectrochemical Performance of Ti-Doped $\alpha$ $\mathrm{Fe}_{2} \mathrm{O}_{3}$ Thin Films by Surface Modification with Fluoride. Chem. Commun. 2009, 2652-2654.

(40) Xi, L.; Bassi, P. S.; Chiam, S. Y.; Mak, W. F.; Tran, P. D.; Barber, J.; Chye Loo, J. S.; Wong, L. H. Surface Treatment of Hematite Photoanodes with Zinc Acetate for Water Oxidation. Nanoscale 2012, 4, 4430-4433.

(41) Seabold, J. A.; Choi, K.-S. Effect of a Cobalt-Based Oxygen Evolution Catalyst on the Stability and the Selectivity of PhotoOxidation Reactions of a $\mathrm{WO}_{3}$ Photoanode. Chem. Mater. 2011, 23, $1105-1112$.

(42) Barroso, M.; Mesa, C. A.; Pendlebury, S. R.; Cowan, A. J.; Hisatomi, T.; Sivula, K.; Grätzel, M.; Klug, D. R.; Durrant, J. R. Dynamics of Photogenerated Holes in Surface Modified $\alpha-\mathrm{Fe}_{2} \mathrm{O}_{3}$ Photoanodes for Solar Water Splitting. Proc. Natl. Acad. Sci. U.S.A. 2012, 109, 15640-15645.

(43) Riha, S. C.; Klahr, B. M.; Tyo, E. C.; Seifert, S.; Vajda, S.; Pellin, M. J.; Hamann, T. W.; Martinson, A. B. F. Atomic Layer Deposition of a Submonolayer Catalyst for the Enhanced Photoelectrochemical Performance of Water Oxidation with Hematite. ACS Nano 2013, 7, 2396-2405.

(44) Nellist, M. R.; Laskowski, F. A. L.; Lin, F.; Mills, T. J.; Boettcher, S. W. Semiconductor-Electrocatalyst Interfaces: Theory, Experiment, and Applications in Photoelectrochemical Water Splitting. Acc. Chem. Res. 2016, 49, 733-740.

(45) Long, C.; Kisch, H. Visible Light Induced Photoelectrochemical Properties of $\mathrm{n}-\mathrm{BiVO}_{4}$ and $\mathrm{n}-\mathrm{BiVO}_{4} / \mathrm{p}-\mathrm{Co}_{3} \mathrm{O}_{4}$. J. Phys. Chem. C 2008, $112,548-554$.

(46) Stern, L.-A.; Hu, X. Enhanced Oxygen Evolution Activity by $\mathrm{NiO}_{\mathrm{x}}$ and $\mathrm{Ni}(\mathrm{OH})_{2}$ Nanoparticles. Faraday Discuss. 2014, 176, 363379.

(47) Kurzman, J. A.; Dettelbach, K. E.; Martinolich, A. J.; Berlinguette, C. P.; Neilson, J. R. Structural Characteristics and Eutaxy in the Photo-Deposited Amorphous Iron Oxide Oxygen Evolution Catalyst. Chem. Mater. 2015, 27, 3462-3470.

(48) Kanan, M. W.; Nocera, D. G. In Situ Formation of an OxygenEvolving Catalyst in Neutral Water Containing Phosphate and $\mathrm{Co}^{2+}$. Science 2008, 321, 1072-1075.

(49) Kanan, M. W.; Yano, J.; Surendranath, Y.; Dincă, M.; Yachandra, V. K.; Nocera, D. G. Structure and Valency of a Cobalt-Phosphate Water Oxidation Catalyst Determined by in Situ X-ray Spectroscopy. J. Am. Chem. Soc. 2010, 132, 13692-13701.

(50) Huynh, M.; Bediako, D. K.; Nocera, D. G. A Functionally Stable Manganese Oxide Oxygen Evolution Catalyst in Acid. J. Am. Chem. Soc. 2014, 136, 6002-6010.

(51) Bergmann, A.; Zaharieva, I.; Dau, H.; Strasser, P. Electrochemical Water Splitting by Layered and 3D Cross-Linked Manganese Oxides: Correlating Structural Motifs and Catalytic Activity. Energy Environ. Sci. 2013, 6, 2745-2755.

(52) Fekete, M.; Hocking, R. K.; Chang, S. L. Y.; Italiano, C.; Patti, A. F.; Arena, F.; Spiccia, L. Highly Active Screen-Printed Electrocatalysts for Water Oxidation Based on $\beta$-Manganese Oxide. Energy Environ. Sci. 2013, 6, 2222-2232.

(53) Lu, X.; Yim, W.-L.; Suryanto, B. H. R.; Zhao, C. Electrocatalytic Oxygen Evolution at Surface-Oxidized Multiwall Carbon Nanotubes. J. Am. Chem. Soc. 2015, 137, 2901-2907.

(54) Bernicke, M.; Ortel, E.; Reier, T.; Bergmann, A.; Ferreira de Araujo, J.; Strasser, P.; Kraehnert, R. Iridium Oxide Coatings with Templated Porosity as Highly Active Oxygen Evolution Catalysts: Structure-Activity Relationships. ChemSusChem 2015, 8, 1908-1915.

(55) Wang, H.-Y.; Hsu, Y.-Y.; Chen, R.; Chan, T.-S.; Chen, H. M.; Liu, B. $\mathrm{Ni}^{3+}$-Induced Formation of Active $\mathrm{NiOOH}$ on the Spinel NiCo Oxide Surface for Efficient Oxygen Evolution Reaction. Adv. Energy Mater. 2015, 5, No. 1500091.
(56) Lu, Z.; Xu, W.; Zhu, W.; Yang, Q.; Lei, X.; Liu, J.; Li, Y.; Sun, X.; Duan, X. Three-Dimensional NiFe Layered Double Hydroxide Film for High-Efficiency Oxygen Evolution Reaction. Chem. Commun. 2014, 50, 6479-6482.

(57) Görlin, M.; Chernev, P.; Ferreira de Araújo, J.; Reier, T.; Dresp, S.; Paul, B.; Krähnert, R.; Dau, H.; Strasser, P. Oxygen Evolution Reaction Dynamics, Faradaic Charge Efficiency, and the Active Metal Redox States of $\mathrm{Ni}-\mathrm{Fe}$ Oxide Water Splitting Electrocatalysts. J. Am. Chem. Soc. 2016, 138, 5603-5614.

(58) Chen, J. Y. C.; Dang, L.; Liang, H.; Bi, W.; Gerken, J. B.; Jin, S.; Alp, E. E.; Stahl, S. S. Operando Analysis of $\mathrm{NiFe}$ and $\mathrm{Fe}$ Oxyhydroxide Electrocatalysts for Water Oxidation: Detection of $\mathrm{Fe}^{4+}$ by Mössbauer Spectroscopy. J. Am. Chem. Soc. 2015, 137, 1509015093.

(59) Xu, Y.; Bian, W.; Wu, J.; Tian, J.-H.; Yang, R. Preparation and Electrocatalytic Activity of 3D Hierarchical Porous Spinel $\mathrm{CoFe}_{2} \mathrm{O}_{4}$ Hollow Nanospheres as Efficient Catalyst for Oxygen Reduction Reaction and Oxygen Evolution Reaction. Electrochim. Acta 2015, 151, 276-283.

(60) Yeo, B. S.; Bell, A. T. In Situ Raman Study of Nickel Oxide and Gold-Supported Nickel Oxide Catalysts for the Electrochemical Evolution of Oxygen. J. Phys. Chem. C 2012, 116, 8394-8400.

(61) Geng, J.; Kuai, L.; Kan, E.; Wang, Q.; Geng, B. Precious-MetalFree $\mathrm{Co}-\mathrm{Fe}-\mathrm{O} / \mathrm{rGO}$ Synergetic Electrocatalysts for Oxygen Evolution Reaction by a Facile Hydrothermal Route. ChemSusChem 2015, 8, 659-664.

(62) Swierk, J. R.; Klaus, S.; Trotochaud, L.; Bell, A. T.; Tilley, T. D. Electrochemical Study of the Energetics of the Oxygen Evolution Reaction at Nickel Iron (Oxy)Hydroxide Catalysts. J. Phys. Chem. C 2015, 119, 19022-19029.

(63) Danilovic, N.; Subbaraman, R.; Chang, K.-C.; Chang, S. H.; Kang, Y. J.; Snyder, J.; Paulikas, A. P.; Strmcnik, D.; Kim, Y.-T.; Myers, D.; Stamenkovic, V. R.; Markovic, N. M. Activity-Stability Trends for the Oxygen Evolution Reaction on Monometallic Oxides in Acidic Environments. J. Phys. Chem. Lett. 2014, 5, 2474-2478.

(64) Monllor-Satoca, D.; Bärtsch, M.; Fabrega, C.; Genc, A.; Reinhard, S.; Andreu, T.; Arbiol, J.; Niederberger, M.; Morante, J. R. What Do You Do, Titanium? Insight into the Role of Titanium Oxide as a Water Oxidation Promoter in Hematite-Based Photoanodes. Energy Environ. Sci. 2015, 8, 3242-3254.

(65) Smith, R. D. L.; Prévot, M. S.; Fagan, R. D.; Zhang, Z.; Sedach, P. A.; Siu, M. K. J.; Trudel, S.; Berlinguette, C. P. Photochemical Route for Accessing Amorphous Metal Oxide Materials for Water Oxidation Catalysis. Science 2013, 340, 60-63.

(66) Smith, R. D. L.; Prévot, M. S.; Fagan, R. D.; Trudel, S.; Berlinguette, C. P. Water Oxidation Catalysis: Electrocatalytic Response to Metal Stoichiometry in Amorphous Metal Oxide Films Containing Iron, Cobalt, and Nickel. J. Am. Chem. Soc. 2013, 135, $11580-11586$.

(67) Gerken, J. B.; Shaner, S. E.; Masse, R. C.; Porubsky, N. J.; Stahl, S. S. A Survey of Diverse Earth Abundant Oxygen Evolution Electrocatalysts Showing Enhanced Activity from Ni-Fe Oxides Containing a Third Metal. Energy Environ. Sci. 2014, 7, 2376-2382.

(68) van de Krol, R. Photoelectrochemical Measurements. In Photoelectrochemical Hydrogen Production; van de Krol, R., Grätzel, M., Eds.; Springer US: Boston, MA, 2012; pp 69-117.

(69) Du, C.; Yang, X.; Mayer, M. T.; Hoyt, H.; Xie, J.; McMahon, G.; Bischoping, G.; Wang, D. Hematite-Based Water Splitting with Low Turn-On Voltages. Angew. Chem., Int. Ed. 2013, 52, 12692-12695.

(70) Jang, J.-W.; Du, C.; Ye, Y.; Lin, Y.; Yao, X.; Thorne, J.; Liu, E.; McMahon, G.; Zhu, J.; Javey, A.; Guo, J.; Wang, D. Enabling Unassisted Solar Water Splitting by Iron Oxide and Silicon. Nat. Commun. 2015, 6, No. 7447.

(71) Glasscock, J. A.; Barnes, P. R. F.; Plumb, I. C.; Bendavid, A.; Martin, P. J. Structural, Optical and Electrical Properties of Undoped Polycrystalline Hematite Thin Films Produced Using Filtered Arc Deposition. Thin Solid Films 2008, 516, 1716-1724. 
(72) Klahr, B.; Gimenez, S.; Fabregat-Santiago, F.; Hamann, T.; Bisquert, J. Water Oxidation at Hematite Photoelectrodes: The Role of Surface States. J. Am. Chem. Soc. 2012, 134, 4294-4302.

(73) Zandi, O.; Hamann, T. W. The Potential Versus Current State of Water Splitting with Hematite. Phys. Chem. Chem. Phys. 2015, 17, 22485-22503.

(74) Morales-Guio, C. G.; Mayer, M. T.; Yella, A.; Tilley, S. D.; Grätzel, M.; Hu, X. An Optically Transparent Iron Nickel Oxide Catalyst for Solar Water Splitting. J. Am. Chem. Soc. 2015, 137, 99279936.

(75) Beverskog, B.; Puigdomenech, I. Revised Pourbaix Diagrams for Chromium at $25-300{ }^{\circ}$ C. Corros. Sci. 1997, 39, 43-57.

(76) Wang, D.; Zhou, J.; Hu, Y.; Yang, J.; Han, N.; Li, Y.; Sham, T.-K. In Situ X-ray Absorption Near-Edge Structure Study of Advanced $\mathrm{NiFe}(\mathrm{OH})_{\mathrm{x}}$ Electrocatalyst on Carbon Paper for Water Oxidation. J. Phys. Chem. C 2015, 119, 19573-19583.

(77) Ruoko, T.-P.; Kaunisto, K.; Bärtsch, M.; Pohjola, J.; Hiltunen, A.; Niederberger, M.; Tkachenko, N. V.; Lemmetyinen, H. Subpicosecond to Second Time-Scale Charge Carrier Kinetics in HematiteTitania Nanocomposite Photoanodes. J. Phys. Chem. Lett. 2015, 6, 2859-2864. 